\title{
The Clinical Features and Management of Duane's Retraction Syndrome Type 2 in Pediatric Patients
}

\author{
Asli Inal, ${ }^{1}$ Osman Bulut Ocak, ${ }^{1}$ Ebru Demet Aygit, ${ }^{1}$ Selcen Celik, ${ }^{1}$ Berkay Inal, ${ }^{2}$ Ahmet Demirok, ${ }^{1}$ \\ Birsen Gokyigit ${ }^{1}$
}

${ }^{1}$ University of Health Sciences, Prof. Dr. N. Resat Belger Beyoglu Eye Training and Research Hospital, Istanbul, Turkey 2University of Health Sciences, Okmeydani Training and Research Hospital, Istanbul, Turkey

\begin{abstract}
Objectives: The aim of this study was to describe the demographic details, features, and clinical management of pediatric patients with Duane retraction syndrome (DRS) type 2.

Methods: A total of 632 charts from patients who were diagnosed with DRS between January 1998 and January 2016 were retrospectively reviewed. DRS type 2 patients who were $<18$ years old were identified. Demographic data and clinical findings from pediatric patients with a follow-up time $>$ I year were collected. Orthotropia or \pm 10 prism diopters (PD) at near and distance fixation in primary position with available optical correction at the last visit was considered a satisfactory outcome.

Results: There were 5 girls (62.5\%) and 3 boys (37.5\%). The average age at the first visit was $8.87 \pm 6.70$ years (range: 2 - I 8 years). The left eye was affected in 4 patients, the right eye in 3 patients, and I patient had bilateral involvement. Amblyopia was detected in 4 patients. Four patients had abnormal head posture (AHP). All of the patients had exotropia (XT). The near deviation angle was 24.75 \pm 16.45 PD (range: 4-60 PD), and the distance deviation angle was 29 \pm 23.12 PD (range: 10-80 PD). Orthotropia/<10 PD XT was seen in 5 patients with refractive correction. Three patients underwent surgery to correct deviation. In the final examination, 2 patients had AHP and orthophoria/<I0 PD XT was observed in 6 patients. Conclusion: Amblyopia and deviation in primary position was common in children with DRS type 2 in our small group; therefore, detailed patient examinations are very important. Surgery would be appropriate for patients with strabismus and/or AHP.
\end{abstract}

Keywords: Clinical features, Duane retraction syndrome, Duane retraction syndrome type 2, exotropia, strabismus.

\section{Introduction}

In pediatric exotropia $(\mathrm{XT})$ patients with limited adduction, the differential diagnosis is important. In this circumstance, Duane retraction syndrome (DRS) type 2 , congenital fibrosis of the extraocular muscles (CFEOM) type 2, and congenital third cranial nerve palsy should be considered. At an international workshop in 2002, the European Neuromuscular Centre elected to use the term congenital cranial dysinnervation disorders (CCDD). CCDD are characterized by congenital, non-progressive ophthalmoplegia for a group of congenital non-progressive, sporadic, or familial neuromuscular diseases with restriction of globe movement in I or more fields of gaze $(I, 2)$. DRS is the most common CCDD, with a prevalence of I:10.000; about 10\% of cases are familial and usually autosomal dominant without associated abnormalities (I). DRS is characterized by congenital limitations in horizontal globe movements and some globe retraction on attempt- 
ed adduction, leading to palpebral fissure narrowing $(I, 3)$. There are 3 types of DRS according to Huber's classification system, which is based on duction deficiency (3-5). Type I is characterized by a significant limitation or complete absence of abduction, normal or only slightly defective adduction, narrowing of the palpebral fissure, and retraction on adduction. In type 2, there is limited or absence of adduction with $\mathrm{XT}$, normal or slightly limited abduction, narrowing of the palpebral fissure, and retraction of the globe on attempted adduction. Type 3 is a combination of limitations or the absence of both abduction and adduction/retraction of the globe, and narrowing of the palpebral fissure on attempted adduction (I, 3-5). Surgery can be performed to correct primary position misalignment-associated abnormal head posture (AHP) and to minimize palpebral fissure narrowing. Surgery does not correct the syndrome and cannot restore eye movements (6). Type $I$ is the most common type (78\%), followed by type 3 (15\%) and 2 (7\%) (3). Because type 2 is the least common type, there are only a few studies about type 2 DRS.

The aim of this study was to make a contribution to the literature by describing the demographics, features, and clinical management of pediatric patients with DRS type 2, which will help make the differential diagnosis easier.

\section{Methods}

The study was approved by the local ethics committee and was performed according to the tenets of the Declaration of Helsinki. All 632 charts of patients diagnosed as DRS at the hospital between January 1998 and January 2016 were retrospectively reviewed, and patients with DRS type 2 were identified. The diagnosis of DRS type 2 was made via observation of the characteristic clinical features of the syndrome. The inclusion criteria consisted of 2 main parameters: I) the diagnosis of DRS type 2 and 2 ) age $<18$ years old.

Exclusion criteria also comprised 2 main parameters: I) any other ocular disease and 2) follow-up time $<$ I year. Demographic data and clinical findings were collected. Age, gender, laterality, refractive error, primary position deviation, degree of face turn, and amblyopia were recorded. The patients underwent a standard ophthalmological examination, including refraction (cycloplegic refraction via retinoscopy and auto refractor/keratometer [Retinomax K-Plus 3; Righton Opthalmic Instruments, Tokyo, Japan]), best corrected visual acuity (BCVA), slit-lamp biomicroscopy, and detailed fundoscopy. Visual acuity measurements were performed with Snellen charts. An eye was classified as amblyopic when the BCVA was $\leq 20 / 30$ in I eye or was at least 2 visual acuity lines worse than the companion eye as determined by the Snellen or Snellen E chart. Ocular motility was evaluated with alternate cover testing and/or Krimsky test, and ductions and versions were examined using classical methods and results were recorded. Ocular deviation in the primary position of gaze was measured using a cover test with the uninvolved eye fixed on a target. Abnormal head posture (AHP) was estimated for all patients while the patient sat erect, fixating on a target 20 feet distant as previously described (7-9).

Postoperative orthotropia within 10 PD deviation at near and distance fixation with available optical correction was considered a satisfactory outcome. Criteria for a second operation were residual XT > I4 PD with optical correction and secondary esotropia $>$ I4 PD.

IBM SPSS Statistics for Windows, Version 23.0 (IBM Corp., Armonk, NY, USA) was used for the data analysis. Categorical variables were presented as numbers, and numerical variables were expressed as mean and SD.

\section{Results}

There were 35 patients $(5.53 \%)$ with DRS type 2. Eight were pediatric patients (age $<18$ years). Among the 8 cases, the average age at the first visit was $8.87 \pm 6.70$ years (range: 2 - 18 years). There were 5 females (62.5\%) and 3 males (37.5\%). The left eye was affected in 4 patients, the right eye was affected in 3 patients, and I patient had bilateral involvement. The average spherical equivalent of the affected eyes was $0.63 \pm 1.99 \mathrm{D}$. Amblyopia was detected in 4 patients out of 5 whose visual acuity could be examined with the Snellen E chart. Four patients had AHP (Table I).

All of the patients had XT. The near deviation angle was 24.75 \pm 16.45 PD (range: 4-60 PD) and the distance deviation angle was $29 \pm 23.12$ PD (range: 10-80 PD). Orthophoria/<10 PD XT was recorded in 5 patients with refractive correction. Three patients underwent surgery for deviation. The deviation angles and treatments are listed in Table 2 . In the final examination, 2 patients had AHP and orthophoria/<10 PD $\mathrm{XT}$ was observed in 6 patients.

Table I. Patients' baseline characteristics

\begin{tabular}{lccccc} 
Case & Gender & Age (Years) & SE (D) & Eye & AHP \\
\hline I & M & I8 & $-1.75 \mathrm{D}$ & $\mathrm{L}$ & + \\
2 & $\mathrm{~F}$ & $\mathrm{I} 8$ & $-0.75 \mathrm{D}$ & $\mathrm{R}$ & - \\
3 & $\mathrm{~F}$ & $\mathrm{II}$ & $+4.50 \mathrm{D}$ & $\mathrm{R}$ & + \\
4 & $\mathrm{M}$ & $\mathrm{II}$ & $+1.25 \mathrm{D}$ & $\mathrm{L}$ & + \\
5 & $\mathrm{~F}$ & 7 & $+1.50 \mathrm{D}$ & $\mathrm{L}$ & - \\
6 & $\mathrm{M}$ & 2 & $-\mathrm{I} .50 \mathrm{D}$ & $\mathrm{L}$ & + \\
7 & $\mathrm{~F}$ & 2 & $-\mathrm{I} .25 \mathrm{D}$ & $\mathrm{R}$ & - \\
8 & $\mathrm{~F}$ & 5 & $+1.25 \mathrm{D} /+2.75 \mathrm{D}$ & $\mathrm{R}+\mathrm{L}$ & - \\
\hline
\end{tabular}

AHP: abnormal head posture; D: diopters; F: female; L: left; M: male; R: right; SE: spherical equivalent. 
Table 2. Patients' deviation angle and treatment

\begin{tabular}{|c|c|c|c|c|c|c|}
\hline Cases & $\mathbf{N}(P D)$ & D (PD) & RC & Surgery & Final angle (N/D) & Final AHP \\
\hline I & 16 & 16 & Yes & No & $10 \times T / 10 \times T$ & + \\
\hline 2 & 4 & 16 & Yes & No & $\mathrm{O} / 10 \times \mathrm{T}$ & - \\
\hline 4 & 20 & 30 & & LR $6 \mathrm{~mm}$ rec. +Y-split & $\mathrm{O} / 10 \times \mathrm{T}$ & - \\
\hline 5 & 60 & 80 & & I. BLR 7 mm rec. & & \\
\hline 6 & 10 & 10 & Yes & No & $\mathrm{O} / \mathrm{O}$ & - \\
\hline 7 & 10 & 10 & Yes & No & $\mathrm{O} / \mathrm{O}$ & - \\
\hline 8 & 30 & 45 & & BLR $7 \mathrm{~mm} \mathrm{rec.}$ & $8 / 14 \times T$ & - \\
\hline
\end{tabular}

BLR: bilateral lateral rectus; D: distance deviation angle; Final AHP: abnormal head posture in the final examination; Final angle: deviation angle in the final examination; LR: lateral rectus; LMR: medial rectus; Rec: recession; Res: resection; N: near deviation angle; O: orthotropia;

$\mathrm{RC}$ : refractive correction; $\mathrm{XT}$ : exotropia.

\section{Discussion}

The differential diagnosis in pediatric XT patients with limited adduction is very important. Congenital third cranial nerve palsy and CFEOM type 2 should be considered in the differential diagnosis of DRS type 2. Early diagnosis of DRS type 2 will avoid unnecessary use of imaging methods, and save time and money.

In the literature, much has been written about the most common DRS form (type I) $(7,10,1 \mathrm{I})$. However there are only few studies about type 2 DRS, and this is the first study to discuss the clinical features and management of pediatric DRS type 2 patients. DRS is usually a sporadic syndrome with left eye predominance, and is more common in females. Bilateral involvement is less common than unilateral occurrence (3). According to von Noorden, the prevalence of DRS type 2 is $7 \%$ (3). Raab (I2) reported 70 DRS cases, among which there was I\% type 2. Anvari et al. (I3) reported I 25 patients with DRS and the incidence of type 2 was $6.5 \%$. Similar to this case series from Iran, among our strabismus population there were 35 patients with DRS type 2 (prevalence of $5.53 \%$ ).

The demographic characteristics of our patients were comparable to those in previously reported studies $(5,6)$. The left eye was affected in 4 patients, the right eye was affected in 3 patients, and I patient had bilateral involvement. Gender distribution was also similar to that seen in other studies. Five of our patients were female and 3 were male. In different studies, the prevalence of bilateral involvement has been reported at between $7 \%$ and $24 \%(13,14)$. In the present study there was I patient with bilateral involvement (I2.5\%).

In the literature, the prevalence of hyperopia $>1.50 \mathrm{D}$ ranges between $40 \%$ and $82 \%$ (I3). In the current study, $50 \%$ of the patients had hyperopia.

The prevalence of amblyopia reported in the literature ranges between $3 \%$ and $38 \%(13,14)$. In our study, we examined the visual acuity of 5 patients, and amblyopia was detected in 4 of those patients. Tredici considered amblyopia to be uncommon in DRS; in his study, the presence of amblyopia was 3\% (I4) Tomac et al. (15) reported that patients with types 2 and 3 DRS or XT were found to have amblyopia more frequently than those with type I. Similarly to that study, all of our patients had XT, and we considered strabismus to be the major amblyogenic factor among our study population.

Degree of face turn and AHP are major characteristics of this syndrome, and the aim of treatment is to obtain straight eyes and fusion (5). Four patients (50\%) had face turn and AHP in this study group. Three of them underwent surgery, and I had orthophoria after refractive correction. Improvement was obtained after medical and surgical treatment, but 2 patients still had AHP at the final examination. Park et al. (5) reported 78 patients with DRS; 2 cases were type 2 , and face turn was found in I patient (50\%).

Strabismus is another major determinant of the cosmetic and/or functional status of DRS (I3). If strabismus is present in DRS type 2, XT occurs more frequently (3). In our study all of the patients had XT.

We obtained a satisfactory outcome in 7 of 8 patients. Three patients underwent surgery for AHP and deviation in primary position. One of them had orthophoria, and I had I4 PD XT after I surgery. The third patient had 60 PD near $\mathrm{XT}$ and $80 \mathrm{PD}$ distance XT. We performed bilateral lateral rectus $7-\mathrm{mm}$ resection, and 4 months later we performed the second surgery, which consisted of $5-\mathrm{mm}$ resection of the medial rectus. At the final examination ( 2 years post- 
operatively), there was a slight residual XT with I4 PD near deviation and I8 PD distance deviation.

In conclusion, we found that amblyopia and XT appear to be common in children with DRS type 2. Detailed eye examinations and regular follow-up of these patients is very important. Surgery would be appropriate for patients with strabismus and/or AHP.

\section{Disclosures}

Peer-review: Externally peer-reviewed.

Conflict of Interest: None declared.

Authorship Contributions: Involved in design and conduct of the study (A.I., B.G., A.D.); preparation and review of the study (A.I., B.G., O.B.O.); data collection (O.B.O., E.D.A., B.I.); and statistical analysis (B.I., S.C., A.I.).

\section{References}

I. Gutowski NJ, Chilton JK. The congenital cranial dysinnervation disorders. Arch Dis Child 2015;100:678-81. [CrossRef]

2. Singh A, Pandey PK, Agrawal A, Mittal SK, Rana KM, Bahuguna C. Congenital cranial dysinnervation disorders. Int Ophthalmol. 2016 Nov II [Epub ahead of print].

3. von Noorden GK, Campos EC. Special forms of strabismus. In: Binocular Vision and Ocular Motility. 6th ed. St Louis, Missouri; Mosby Inc: 2002. p. 458-500.

4. Aygit ED, Kocamaz M, Inal A, Fazil K, Ocak OB, Akar S, et al. Management of Duane retraction syndrome with prismatic glasses. Clin Ophthalmol 2017;1 1:697-700. [CrossRef]

5. Park WH, Son DH, Yoon SW, Baek SH, Kong SM. The clinical features of Korean patients with Duane's retraction syndrome. Korean J Ophthalmol 2005; 19:132-5. [CrossRef]
6. Kalevar A, Ong Tone S, Flanders M. Duane syndrome: Clinical features and surgical management. Can J Ophthalmol 2015;50:310-3. [CrossRef]

7. Akar S, Gokyigit B, Pekel G, Demircan A, Demirok A. Vertical muscle transposition augmented with lateral fixation (Foster) suture for Duane syndrome and sixth nerve palsy. Eye (Lond) 2013;27:I I88-95. [CrossRef]

8. Molarte $A B$, Rosenbaum AL. Vertical rectus muscle transposition surgery for Duane's syndrome. J Pediatr Ophthalmol Strabismus 1990;27:171-7.

9. Velez FG, Foster RS, Rosenbaum AL. Vertical rectus muscle augmented transposition in Duane syndrome. J AAPOS 200।;5: 105-13. [CrossRef]

10. Dotan G, Klein A, Ela-Dalman N, Shulman S, Stolovitch C. The efficacy of asymmetric bilateral medial rectus muscle recession surgery in unilateral, esotropic, type I Duane syndrome. J AAPOS 20I2; 16:543-7. [CrossRef]

II. Kekunnaya R, Kraft S, Rao VB, Velez FG, Sachdeva V, Hunter DG. Surgical management of strabismus in Duane retraction syndrome. J AAPOS 2015; 19:63-9. [CrossRef]

12. Raab EL. Clinical features of Duane's syndrome. J Pediatr Ophthalmol Strabismus 1986;23:64-8.

13. Anvari F, Hatef E, Mohammadi SF, Eskandari A. Duane's retraction syndrome, a case series from Iran. Int Ophthalmol 2008;28:275-80. [CrossRef]

14. Tredici TD, von Noorden GK. Are anisometropia and amblyopia common in Duane's syndrome? J Pediatr Ophthalmol Strabismus 1985;22:23-5.

15. Tomaç S, Mutlu FM, Altinsoy HI. Duane's retraction syndrome: its sensory features. Ophthalmic Physiol Opt 2007;27:579-83. 